\title{
Chapter 6 \\ CuidarNos: Art and Social Work \\ to Address Trauma Among Gender-based \\ Violence Advocates After Hurricane María \\ in Puerto Rico
}

\author{
Heriberto Ramírez-Ayala, Elithet Silva-Martínez, \\ and Jenice M. Vázquez-Pagán
}

\subsection{Introduction}

On September 20, 2017, one of the most powerful hurricanes in its history impacted Puerto Rico. Close to three million people lost access to basic services such as electricity and clean water. Thousands of families lost their homes, and many communities remained unreachable after a massive collapse in all communications systems throughout the island. Natural disasters result in serious damage to the normal performance of a community, due to the large number of people injured and the considerable loss of human life and property they cause (Park and Duarte 2011). Natural disasters can also affect the health of the people, necessitating not only immediate attention to the victims but also medium- and long-term actions stemming from the absence of basic services, displacement of people or migration, and a lack of food and housing. In the aftermath of María, many faced 12-14-hour lines to access fuel or food. For countless families, the public education system provides access to food for their children, but a great number of schools remained closed due to structural damages or a shortage of staff. This had a negative effect on many children who were unable to access hot meals or drinking water. The combination of these experiences triggered growth in emigration rates to the United States (Delgado 2018), in

\footnotetext{
H. Ramírez-Ayala $(\bowtie)$

TIPOS, Toa Alta, Puerto Rico

e-mail: heriberto.educa@gmail.com

E. Silva-Martínez

Beatriz Lassalle Graduate School of Social Work, University of Puerto Rico,

San Juan, Puerto Rico

e-mail: elithet.silva@upr.edu

J. M. Vázquez-Pagán

Department of Social Work, Interamerican University of Puerto Rico, San Juan, Puerto Rico

e-mail: jmvazquez@intermetro.edu
} 
part related to the ongoing economic crisis prior to Hurricane María that intensified in the following several months (Rodríguez-Díaz 2018; Robles et al. 2017).

The United Nations Office for Disaster Risk Reduction (UNISDR 2009) defines "disaster" as follows:

A serious disruption of the functioning of a community or a society at any scale due to hazardous events interacting with conditions of exposure, vulnerability and capacity, leading to one or more of the following: human, material, economic and environmental losses and impacts (pp. 9).

The UNISDR definition recognizes that the impact of a disaster can be localized (e.g., a landslide that blocks access to a rural community) or generalized (e.g., the effects of Hurricane María in Puerto Rico) (Adamson 2018). The magnitude, severity, or sequence of events is what often suggests the most immediate risk of traumatic impact for those caught in the disaster. However, the origin of the disaster, the pre-existing vulnerabilities, and how the disaster develops over time also emerge as determinants of the overall traumatic impact (Adamson 2018).

A study published in 2018 in the New England Journal of Medicine estimated at least 4645 deaths in Puerto Rico were related to the hurricane; yet for many months, the local government assured that the death toll was closer to 64 (Kishore et al. 2018). The authors of the study strongly criticized the methods used to account for these deaths and the lack of transparency by government authorities in Puerto Rico in disclosing information. The people of Puerto Rico experienced great devastation, loss, and trauma after Hurricane María, and this trauma certainly remains present in their daily lives. Almost 2 years after experiencing this socio-natural disaster, many families and communities are still dealing with a lack of access to basic resources such as safe housing and access to health and education, in addition to the repercussions of trauma after such a difficult experience. In 2019, there are many families in urban communities that still live under blue tarps while they wait to save money to

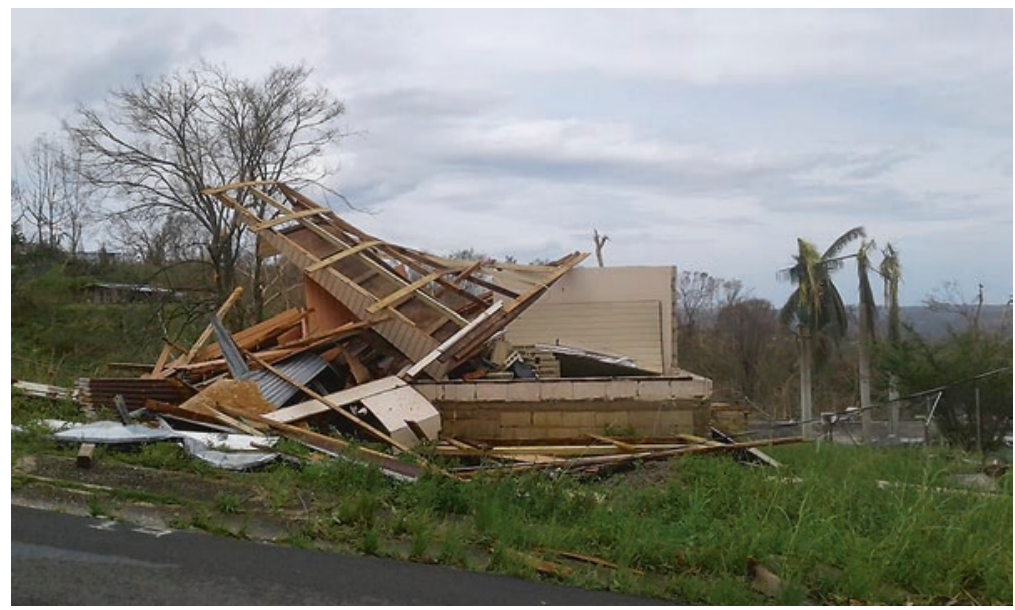

Fig. 6.1 House shattered by the hurricane winds 
rebuild their roofs; numerous families in the mountains—especially families headed by women - are still waiting for access to basic services (Fig. 6.1).

A recent study carried out by Instituto de Estadísticas de Puerto Rico [Puerto Rico Institute of Statistics] (2016) confirmed that of the $45.1 \%$ of the Puerto Rican population living below the poverty line, $46.8 \%$ are women. The literature on disasters and violence against women points out that women and girls are more vulnerable to suffering gender-based violence amid disaster, in many cases exacerbated by the lack of access to protection or support at a public level (Cutter 2017; Fisher 2010; True 2016). In addition, there has been limited support for organizations that, with great effort, kept their projects afloat during and after the disaster. Regarding this issue, there is literature on other regions where natural disasters have occurred that show that women live a double disaster and that their losses include intangible dimensions, such as traumatic responses and exacerbation of health conditions including mental health, which could be considered peripheral (Bradshaw and Fordham 2015; Juran and Trivedi 2015). For example, Neumayer and Plümper (2007) highlight that gender differences have an effect in recovery after natural disasters by having a direct link with economic and social inequality as well as with structural violence against women.

Studies have shown the important role of health promotion in recovering a sense of control after a disaster. Jackson et al. (2016) point out that involving disaster victims (including children) in community-based decisions related to health, education, safety, etc. is important and could, in fact, contribute to healing. Collaborating, recognizing strengths and local assets, conducting community-needs assessments, and respecting local knowledge are all part of a continuous system allowing for the promotion of health in disaster situations. In addition, working with pre-existing community centers as trusted places for community services and reconnections can be important after a disaster occurs.

The Ottawa Charter for Health Promotion (WHO 1986) defines "health promotion" as "the process of enabling people to increase control over, and to improve their health." This document is considered important insofar as it recognizes that to achieve a state of complete physical, mental, and social well-being, an individual or group must be able to identify and realize aspirations, satisfy needs, and change or face the environment. It also affirms that health is not only the responsibility of the health sector. It establishes that health promotion policy must combine diverse but complementary approaches that include legislation, fiscal measures, taxes, and organizational changes as part of coordinated action that leads to health, income, and social policies that promote greater equity. As described in Chap. 1 (this volume), arts-based initiatives can be productively used to support and facilitate health promotion by enhancing these intersectoral approaches.

\subsection{Seeing a Need}

A few days after Hurricane María hit, Coordinadora Paz para la Mujer (CPM) [The Puerto Rican Coalition Against Domestic Violence and Sexual Assault] reached out to nearly 40 organizations throughout the island and made the call to support 
partners who had experienced losses, which included providing shelters for survivors of intimate partner violence and their children. Many of the shelters had already faced major budget cuts. In fact, in 2011, there were close to 15 shelters available, but in September of 2017, only four remained open. Even with several challenges faced by the organizations working with survivors and their children, many returned to rebuild or to provide support with limited resources. Before the hurricane, CPM had been providing support to service providers and community leaders on issues of vicarious trauma, especially due to the alarming number of cases of violence against women. Vicarious trauma involves the indirect trauma that service providers could experience when exposed to the traumatic experiences of their participants. Facing a landscape of devastation from Hurricane María, many advocates and service providers in shelters and other support organizations dealt with the effects of vicarious trauma as well as primary trauma. Following the hurricane, many service providers experienced primary trauma, which consisted of losing their homes, belongings, and even loved ones due to disaster-related factors or being separated due to emigration to the United States. All experienced limited access to basic services such as electricity, running water, and communications, and some even lost their homes and/or family members. At the same time, they were supporting other hurricane survivors who were coping with intimate partner violence, sexual assault, stalking, and sexual harassment in addition to the aftermath of the socio-natural disaster. This scenario led to CPM and the University of Puerto Rico collaborating to develop an art and social work integrated intervention geared toward advocates and service providers to address the combination of primary and vicarious trauma.

In any circumstance related to natural disaster, violence, and/or trauma, service providers experience physical, emotional, and cognitive changes as result of secondary traumatic stress (Naturale 2015; Palm et al. 2004). Violence and trauma can also affect the functioning of their work (Bride 2011). Among the areas affected by stress are the physical, mental, emotional, and behavioral. It has been shown that individual efforts to manage stress are necessary, but probably not enough. In 2011, a study conducted by the American Psychological Association suggested that organizational approaches to stress management are necessary to complement individual approaches; in addition to the efforts made by employees individually, it is important that the organization take comprehensive and structural measures to reduce employee stress and create well-being in the workplace (Cox and Steiner 2013). The results of this study tend to be consistent with the requirements of the Ottawa Charter of Health Promotion (WHO 1986) insofar as they make visible the need for multiple and diverse approaches, at different levels of society, to deal with the stress caused by a traumatic event in life. The Encuentro CuidarNos, part of an initiative propelled by CPM after Hurricane María hit Puerto Rico, aimed to support organizational efforts to address and work through primary and secondary traumatic experiences from a diversity of approaches.

Working in the area of gender-based violence requires multidisciplinary approaches to address its complexity and multiple psychological, social, and environmental roots to allow for approaching the problem in a holistic manner. One of the approaches provided by this holistic vision is the "ecological approach" to 
dealing with violence, instituted by Heise et al. (1994) and based on the work of Bronfenbrenner (1979). This model has been employed by the World Health Organization (WHO) since 2003 and allows violence to be addressed at different levels, namely: the microsocial or individual level; the mesosocial level or the community context; and the macrosocial or institutional level (Olivares and Incháustegui 2011, p. 21-24). Considering these aspects of the ecological model, CuidarNOS was designed to meet the personal and professional needs of service providers, as well as those of women survivors of gender violence and their children. Likewise, it sought to meet the organizational needs of the CPM (and the entities that comprise the coalition) to face the changes caused by Hurricane María.

\subsection{Encuentro CuidarNOS}

The Encuentro CuidarNOS is based on an approach consisting of an integrated intervention of art and social work with the goal of meeting the needs of employees as advocates and service providers from different organizations connected to the coalition. As part of its objectives, this initiative sought to address the combination of primary and vicarious trauma and support psychological health and safety in a natural disaster context. CuidarNOS was designed to work with the physical, mental, and social aspects of service providers who supported survivors of intimate partner violence as well as with the well-being of the community-particularly women survivors of gender violence, their children, and the work teams within the organizations that provide services to them.

There is a growing body of literature that evidences the benefits of using art as a tool to facilitate reflection as well as to express feelings, promote conversation, and connect with others around us (Karcher 2017; Martinec 2018; Wahl-Alexander 2017). In a project in Sri Lanka related to post-disaster trauma, Huss et al. (2016) highlight how art can be a tool for therapeutic interventions, especially in helping to reconstruct the narrative of the event and in provoking mobilization toward recovery and healing. This element was central to developing the Encuentro CuidarNOS. Another important element was acknowledging the neurobiology of trauma and the memory allocated in our bodies. It made us integrate movement as part of the interventions even before repeatedly asking participants to talk about their experiences. In this sense, Wahl-Alexander (2017) touches on how integrative art, physical activity, and somatic healing can be powerful in working in different disaster-related scenarios. As it pertains to other art media such as painting or drawing, we used drawing as a tool for eliciting communication. With his experience of using drawing in a tsunami-related disaster, Alexander (2018) points out that facing disasters and building resiliency requires imagination and refers to multi-dimensional communication through art because it makes it possible to rely exclusively on speech and "objective" understandings of safety. As pointed out by Ahmed and Siddiqi (2006), using art as a tool for therapy "provides a medium for communication and might facilitate the healing of emotional scars" (p. 529). 
Before designing the Encuentro CuidarNOS, in alliance with CPM and a number of other organizations, the authors had been working directly with communities providing health care and legal aid for families seeking assistance from the U.S. Federal Government and support groups, as well as distributing donations and food. All the towns that we visited had an organization that served survivors of violence at different levels. A month after the hurricane, we started the Purple Caravan, which was composed of volunteers from different disciplines and professions. We also made connections with the organizations that were working directly with the communities dealing with violence against women. In that same week we went back to those communities and had a special gathering with these service providers and/or community leaders through the Encuentro CuidarNOS.

The initial purpose of the Encuentro CuidarNOS was to provide a safe space for service providers who worked at community-based and non-profit organizations to process their experiences from their own narratives on disaster-related trauma as well as vicarious trauma in working with survivors of intimate partner violence and sexual assault who, simultaneously, experienced disaster-related trauma. We decided to name it an Encuentro, or meeting, rather than a workshop or training, given the usual charge given to these terms in the professional arena. The term Encuentro laid the ground for an informal setting to share stories that were happening at that moment. Having experienced the hurricane ourselves, we knew that there had not necessarily been an opportunity to process the experience in depth because the island was still in a state of emergency. On the other hand, we were cognizant of the fact that these participants were very clear on their role as service providers, and we were strongly committed to humanizing the Encuentro for the participants to allow them to take part as survivors rather than as responders. Between November 2017 and September 2018, we worked with more than 200 advocates and volunteers, with a broad range of professional and personal backgrounds, from more than 15 organizations across Puerto Rico. When analyzing the participants' profiles, we found that there were social workers, psychologists, lawyers, administration officials and staff, legal advocates, child development specialists, educators, interns, volunteers, and community leaders. We visited all the shelters for survivors of intimate partner violence and their children who are part of the coalition of organizations. Also, we visited organizations that provided direct service as well as prevention services and community outreach on topics related to violence against women.

When it came to making the Encuentro possible, CPM was instrumental in its implementation. A key factor in gaining access to the groups was that CPM is a very well-respected coalition across the island. Its presence for almost 30 years in addressing intimate partner violence and sexual assault through capacity building, community outreach, and involvement in developing and strengthening social policies based on social justice and human rights has been the foundation of trust for organizations in various communities. In addition, the three of us have been working on the topic of interpersonal violence and violence against women for the past 15 years; therefore, many of the organizations knew us or had previously worked with us. 
CPM took on the responsibility of organizing visits to the different organizations and establishing funding for this effort. Staff members established contact with each organization (either by phone or in person, when there was no telephone or digital connection). Given that CPM had also been distributing resources and donations through its Hurricane María Relief Fund, all the organizations were in close communication. In collaboration with CPM and many other allies, the commitment to the recovery of the organizations and the communities where they were situated also motivated us to help organize the Purple Caravan. This initiative gave us first-hand access to many of the service providers. We had been working as partners before the Encuentro, and this helped in strengthening trust with many of the participants of the program.

\subsection{Processing Trauma and Healing Through Art}

The American Art Therapy Association (2017) explains that through integrative methods, art therapy engages the mind, body, and spirit in ways that are distinct from verbal articulation alone. Kinesthetic, sensory, perceptual, and symbolic opportunities invite alternative modes of receptive and expressive communication, which can circumvent the limitations of language. Visual and symbolic expression give voice to experience and empower individual, communal, and societal transformation. With this knowledge, we incorporated our expertise in social work and artistic education to face the collective trauma left by Hurricane María. A specialized three-hour Encuentro was designed to address the diverse needs, taking into consideration the neurobiology of trauma and its effects.

According to material on the subject, in addition to the effects of trauma on its prefrontal cortex, the brain also undergoes severe structural changes in the hippocampus - the structure that is responsible for the consolidation and organization of memory (Silva-Martinez 2018). Additionally, language is another fundamental area that is affected by trauma. To access memories impacted by trauma and to explore various expressive languages, we created three spaces to address the individual, relational, and collective dimensions. In turn, we selected one or several branches of art that could promote somatic experiences such as body movement, theatrical techniques, drawing, and sound to support healing processes.

The structure of the Encuentro combines reflection and play to create a safe space. The authors discussed in advance how to assign which part of the Encuentro our partner would be leading. For example, when a creative dynamic was underway, the co-facilitator would be responsible for preparing the materials, participating in the activity, or observing the reactions of the participants. This agreement allowed fluid transitions, kept the space organized, and helped to promote confidence between the facilitator and the group. This body of work involved five phases: harmonization; sensitization; expression; kinesthetic dynamic; and love networks, which consisted of collective exercises that began with the body and transitioned to the spoken word to build hope. 


\subsubsection{Phases of the Encuentro CuidarNOS}

The first part of the Encuentro was harmonization, which consisted of two preparatory exercises to foster a climate of trust. After all the participants stated their names and provided some information about themselves, they were invited to take deep and conscious breaths, followed by a collective exercise called el baño (the bath). In this theater dynamic, we asked participants to mentally situate themselves in a waterfall at El Yunque, Puerto Rico's beloved national rainforest. The group formed a circle, and one by one, a person took his or her place at the center of the circle. The participants who formed the circle would then use their hands to trace the person's shape, starting with the top of the head and going to the bottom. The movement was repeated three times and served the purpose of simulating water falling. The participants performed the movement while repeating a slow and calming sound of "shh," thus creating the auditory illusion of listening to the sound of a waterfall and being immersed in water. The intention was to create a state of relaxation, connect with our roots, and prepare the soul for the next phase of the exercise. Once this phase was finished, participants expressed feelings of deep relaxation, calmness, and serenity. After asking participants to become mentally and emotionally present and inviting them to trust in the process, one of the facilitators provided a brief explanation of the neurobiology of trauma followed by a brief description of the next exercises.

The second phase-sensitization-aimed to connect participants with their senses. According to the pioneering work carried out by scientists Linda Buck and Richard Axel (1991), each olfactory cell has a single receptor, organized by families, which can recognize a specific number of odors. When it perceives one of them, it sends a signal to different micro-areas of the brain responsible for memory and interpretation, associating smells with past experiences. In addition to olfactory stimuli, we also used tactile stimuli. During this phase, the participants remained seated with their eyes closed and were exposed to various olfactory and tactile stimuli such as containers with soil, stones, cotton, wet towels, air from hand fans, and water mist with lavender. Because many people drink coffee, and because of its cultural importance in Puerto Rico, we included coffee in one of the containers. Many participants commented that they had mental images of their childhood, like memories of their grandmother preparing coffee. Others mentioned that in the aftermath of the hurricane they drank coffee, while others missed drinking recently brewed, hot coffee. In addition, as many homes were flooded, participants commented that the tactile stimuli of the wet towels brought back the sensation of squeezing wet towels during the hurricane.

To retrieve an emotive memory, utilizing a visualization exercise, participants were invited to breathe deeply and take a journey through their individual memories of the day Hurricane María hit Puerto Rico. The facilitator guided the experience with specific questions that emphasized the sense of sight in connection to their emotions. For example: What clothes were you wearing that day? What were you doing? Where exactly were you? Did you feel safe? Who accompanied you? Did 
you see where the winds or the water came from? At the end of the last question, musical instruments created a symbolic representation of the hurricane. In a subtle way, we used the kalimba instrument (mbira) to evoke the first drops of water, then wind chimes were introduced, followed by a rain stick to create the atmosphere of rain, the sound of a hand drum, and tree branches. Lastly, we introduced the sound of sheet metal and pieces of wood striking the ground. They represented the materials used to build many of the homes and structures of the island. The drum intensified the beats, raising the rhythm to a climax in unison, the metal sheet and the wood complementing it. Slowly, the intensity of the instruments decreased until culminating with the subtle sound of the kalimba, simulating the last drops of rain (Fig. 6.2). The facilitator asked the participants to retrieve a specific memory and emotion that was evoked during the exercise. They were then asked to observe the experience

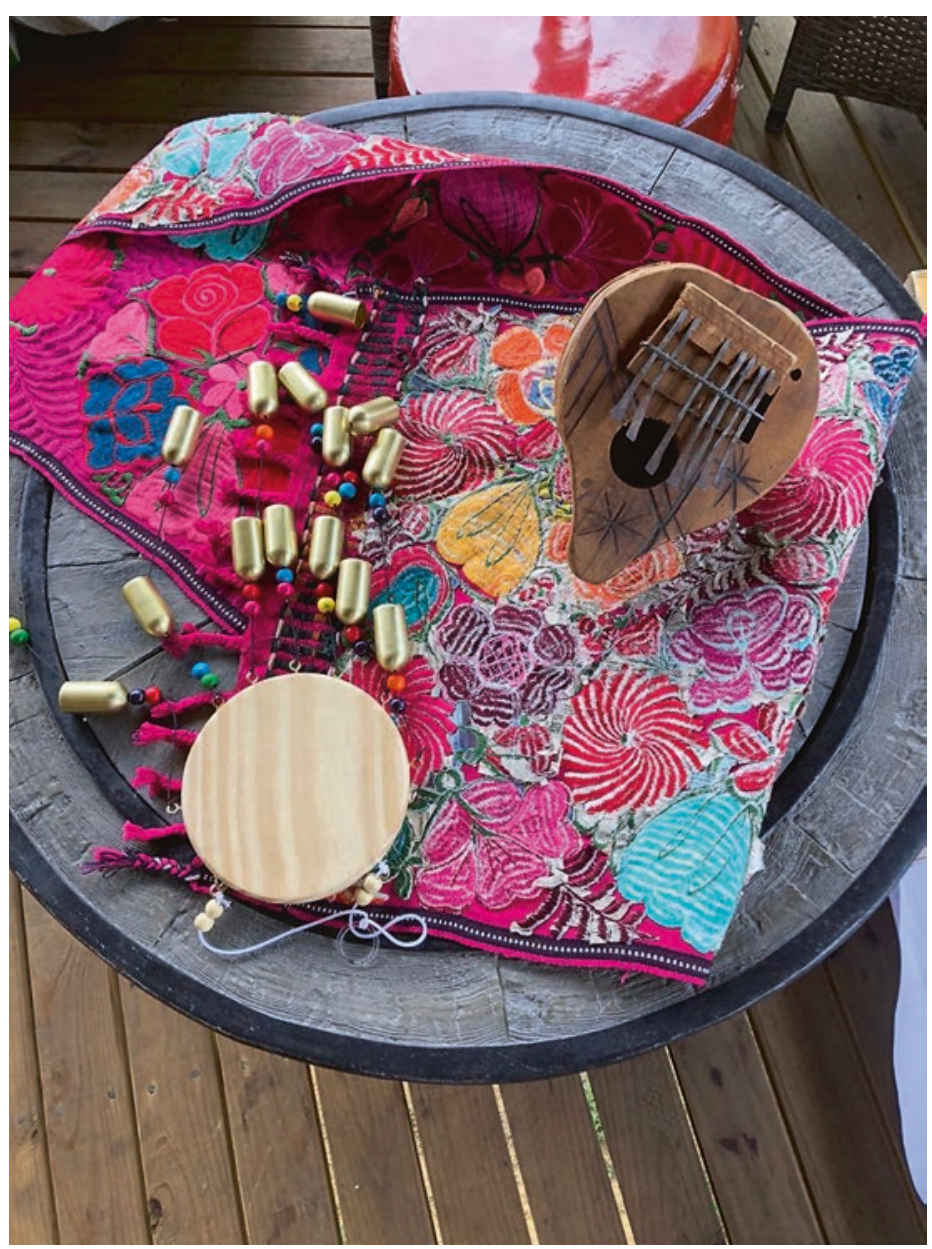

Fig. 6.2 Use of sound to evoke emotive memories 
from a distance until they reached the present moment. The facilitator encouraged them to share their experiences in the company of other people and reminded them that they were in a safe place.

The expression phase represents the climactic moment of the Encuentro, creating a space for creative expression as a prelude to sharing the experiences. We presented two options. The first was to draw, on paper, the image that most impacted them during the hurricane experience, using two colors that could represent the meaning of this experience. The second option was to choose an object that we had placed on a table related to the experience. On the table we had water bottles, canned food, candles, lanterns, pieces of wood, tree branches, sheet metal, wet towels, a suitcase, and a machete. ${ }^{1}$ These objects were commonly used by many when there was no electricity, access to running water, or access to fresh food. The suitcase was placed because of the thousands of people who had emigrated to the United States (Instituto de Estadísticas de Puerto Rico 2017). The majority of participants selected both options, and after they had completed both, we invited them to join a circle so that they could tell their stories. Some of the participants began expressing their emotions, such as desperation, a sense of uncertainty, pain, sadness, and fear, among others.

We observed that during the exercise, empathy was developed and expressed. For example, when participants became overwhelmed with emotion, others offered their support by reaching out their hands or embracing them with a hug. Most participants expressed not knowing how much the hurricane had affected them until the moment they shared their experiences in the circle. Others stated-often in a choked-up voice - that it was in that very moment in the circle that they had heard the stories of their co-workers for the first time, as well as their difficulties, frustrations, and fears that they were still going through. Witnessing and being emotionally present in the story are important to processing the traumatic experience (SilvaMartínez 2018).

The fourth phase-kinesthetic dynamic_-proposes returning from emotion to the body through movement. In the exercise titled Inquilinx (the tenant), two participants held hands simulating the walls of a home. These two participants represented the right and left walls and in the center, a third participant represented the tenant. One of us facilitated by calling out the right wall, left wall, or tenant. Those who represented the right wall exchanged positions with the others who also represented the right wall in a different home. As they moved through the space, we asked them to use their bodies by moving or even dancing to act out being pushed by the wind. When the facilitator called out the word "hurricane," all participants let go of each other and moved or danced through the space while they created a new formation. The results of the experience were new residences with three walls, single tenants, homes with more than one tenant, or empty houses. In the final part of the exercise,

\footnotetext{
${ }^{1}$ A metal, bladed tool—comparable to a small sword—used by jíbaros (Puerto Ricans from the countryside) who work in agriculture. It is quite symbolic of said jíbaros, and after the hurricane it was used to cut branches, chop fallen trees, and clear out leftover brush.
} 
we asked participants to remain where they were and look around. We reflected on the new homes and linked them to our experiences after the hurricane. The purpose of the exercise was to understand, from the body, the reconfiguration that we as a country were experiencing: a new landscape, a new social design, a new opportunity to reconfigure our present and future. In all groups, this exercise generated laughter and excitement. Literature related to this topic confirms a positive influence of dance movement therapy (DMT) on the decreasing of trauma-related symptoms (Martinec 2018). These results are explained by the assumption that the use of DMT enhances resilience by including the body in therapeutic process, supports a state of pleasure and satisfaction, mitigates a neurochemical arousal of distress, and finds movement and body-based modalities that are pleasant and acceptable (Martinec 2018).

For the fifth phase, we introduced a discussion on la brega (the daily struggle), in which we talked about life after the hurricane and pursued hope as the tenet of the exercises and reflections. First, participants were instructed to use their bodies to give three hugs: a hug to oneself, a hug from heart to heart, and a final hug that involved the whole group in a collective embrace. As we formed a big circle, we told them that in this exercise, everyone would also have an opportunity to fly, which naturally made them doubtful. As we all embraced each other, one of us explained that "flying" consisted of a person holding on to people on each side who would come close enough to have the strength to lift that person up. In this phase of the Encuentro, participants being able to suspend themselves in the air one by one while being supported by the shoulders of their co-participants introduced the topic of relying on the power of coming together, despite differences and even tensions among each other.

The purpose of the exercises was to transfer the experience to the body and somatically experience concepts such as affection and support. It encouraged feeling love and provided a concrete experience that participants could remember regarding a support network that sustained them. They were invited to reflect on the feeling of uncertainty after the natural disaster and the need to make a great leap of faith into the new, with the confidence of belonging to a group that supports them. The exercise culminated with giving someone in the group a heart-shaped cushion and sharing words of love and hope with that person (Fig. 6.3). The heart serves as a universal symbol of love and indispensable value to face new realities. This final action helped to exercise gratitude and recognize the importance of humanity in the processes of recovery and resilience. During the exercises, many expressed feeling happy and hopeful in having the emotional tools to build a new destiny.

As we were working with primary and secondary traumatic experiences after the hurricane hit, we emphasized the importance of taking care of the self individually as well as collectively. In order to attend to this, we proposed the game "galactic guardian." This game required each participant to anonymously exchange a piece of paper with the name of a co-worker written on it. Their task was to take care of their co-worker for two weeks. Follow-up was an essential component of this exercise; thus, a month after the workshop, we called participants at the different 


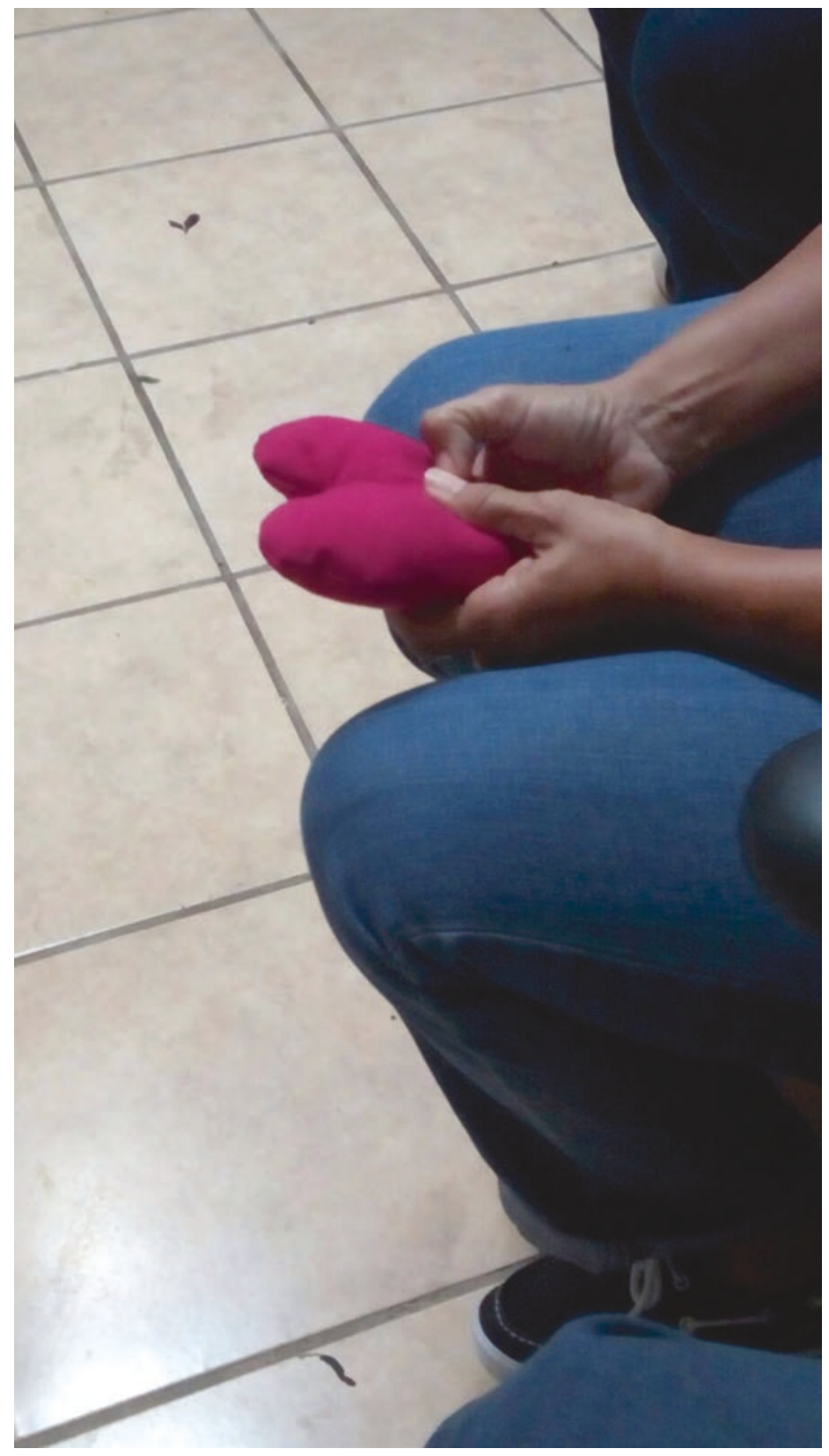

Fig. 6.3 Self-care and collective care through the imagery of love 
organizations to share how they took care of each other and what it meant for them to engage in this exercise. Accompaniment throughout the process helped the participants to commit to taking care of each other within the organizational context.

\subsection{Encuentro CuidarNOS from the Inside: Experiences of Participants}

At every Encuentro, we engaged in a debriefing and evaluation at the end of the session. In addition, the participants submitted a written evaluation of their experience. We found that all the participants recognized the importance of setting time aside to process their experiences after the hurricane. In several groups, the participants asked us to return so that other colleagues and partners could be part of the Encuentro. The following testimonies illustrate the meaning of the experience for participants:

"Participating in Encuentro CuidarNOS gave a space to breathe and unwind at times when it had been difficult to get it out, and maybe I had not allowed that space. Sometimes, trying to follow the hectic pace of everyday life, it becomes difficult for us to take a space to disconnect, recognize ourselves and allow ourselves to feel and let go. Having this space through CuidarNOS was wonderful with an incredible healing power."

"My experience with CuidarNos was very good, because it was the first time I could open up as I did that day. To be able to have that space and see the perspective from the point of view of my colleagues and how they were impacted my story. After this experience, my colleagues get along very well, we have good chemistry and we can feel confident expressing our feelings... One recommendation is that spaces like these continue to be held. After the hurricane, the statistics of violence and suicide have increased and now any wind that passes by, everyone is waiting. There are still people who have not overcome Hurricane María."

"CuidarNOS was magical, magical in the sense that I could completely transport myself to that day...it has a very substantial part, integrating the arts, sounds, textures. Rather than express it verbally, choosing colors to reflect the feelings and memories of that moment, it was magical. This space was extremely important."

"CuidarNOS was very important and significant, because after Hurricanes Irma and María, it was powerful to take time, a space for us and not devote all our energy, our effort and thought to the community and to other people. It was really the first time we were able to come together for ourselves, between us, embrace each other and listen to our feelings...to listen and to say the things that most impacted us, and those that we would like to see in our work from our perspectives."

"As an artist I like to experiment with the symbol and meaning of things, how objects, sayings or everyday things you can do can transform the meaning of things. When going through the process of CuidarNos, it takes me back to the postulate that I go first, and if I am living and integrating self-care, then I am the living example before other people, as an artist and as an educator community. If you are safe, taken care of and in health, is going to guarantee that this will multiply in the community." 
Despite the differences among groups, for many the Encuentro meant a valuable opportunity to address the experience of working with others' trauma related to the hurricane as well as to violence, while they dealt with their own experiences of loss. Our analysis of the process leads us to reiterate the need for continued reflection on interventions with service providers, community leaders, and partners using art toward healing and strength.

\subsection{Reflections}

CuidarNos uses art and movement to enhance services providers' skills in managing the symptoms of trauma and to exercise more control over their own health and environment. The Encuentro was a space to connect and collectively process experiences that, as observed in the previous narratives, had not been shared in depth prior to participation. This provided the opportunity to strengthen the relationships at both organizational and personal levels. It also helped to establish grounds for caring at both the individual and collective levels. Self-care was an important element in closing the Encuentro experience. Bringing individual self-care to the conversation was as important as discussing collective caring as a tool for humanizing professional interventions, community building, and volunteer work.

At the organizational level, it was important to invite administrators and supervisors to be co-participants with staff. Even though we understood the complexities around bringing them together, especially in cases where they could be facing tensions or conflict, we decided to ask everyone at the organization to attend. The introduction of what the Encuentro was about helped in bringing us a bit closer to leveling power imbalances. We were emphatic in the role of the participants, especially in clearly stating the need to trust the process and feel free to engage (or not) in the exercises. At one of the organizations, a staff member preferred not to participate; other than this, we did not encounter opposition or resistance to participate. However, in a couple of cases, it took time for some of the participants to ease into expressing their experiences. At other organizations, staff were unexpectedly upfront regarding tensions with other colleagues.

Each of the organizations that we worked with presented very particular characteristics. The location of the organization and the number of staff and volunteers were one of the major differences in terms of the groups. CPM did its best in making sure that most of its partners had the opportunity to experience the Encuentro. A few of the organizations had fewer staff members, so these participants would join others from a sister organization. This changed the dynamic a little, especially in the last part of the Encuentro. These cases required a reconfiguration of the exercises, by dividing the group.

The experience of bringing to life the Encuentro in partnership with others shows that even with seemingly endless obstacles in recovering, we are reconfiguring the disaster as an opportunity to see ourselves as capable of moving forward collectively. It has allowed us to enable conversations that, although painful, must take 
place in order to recognize the need for our individual and collective humanity to move toward the development of citizenship and alternative social movements. Today we find fertile ground to join and come closer to healing and transformation.

\subsection{Discussion and Conclusion}

The experience engaging in a disaster context is multidimensional over time and space. It has been suggested that long-term support is necessary, and that alternative expressions collected over time are useful for disaster awareness and risk reduction education (Alexander 2018). Also, the recovery from trauma may be a shared, community-wide endeavor geared toward individuals, families, and communities receiving services, as well as service providers and supervisors alike (Adamson 2018). In retrospect of the context in which Hurricane María took place-a profound economic crisis, inequality, and violence against women (a serious issue in Puerto Rico)—we needed to address those concerns in the Encuentro, as they were pressing issues in the work of the service providers, community leaders, and partners. It is imperative to discuss the social aspect of disasters, and how interventions using art can be very powerful in making such discussions happen. In addressing trauma and healing through a social justice art therapy framework, Karcher (2017) explains the importance of acknowledging that structural, multidimensional factors are interconnected, and that wellness and healing depend on working together to envision transformation and collective healing.

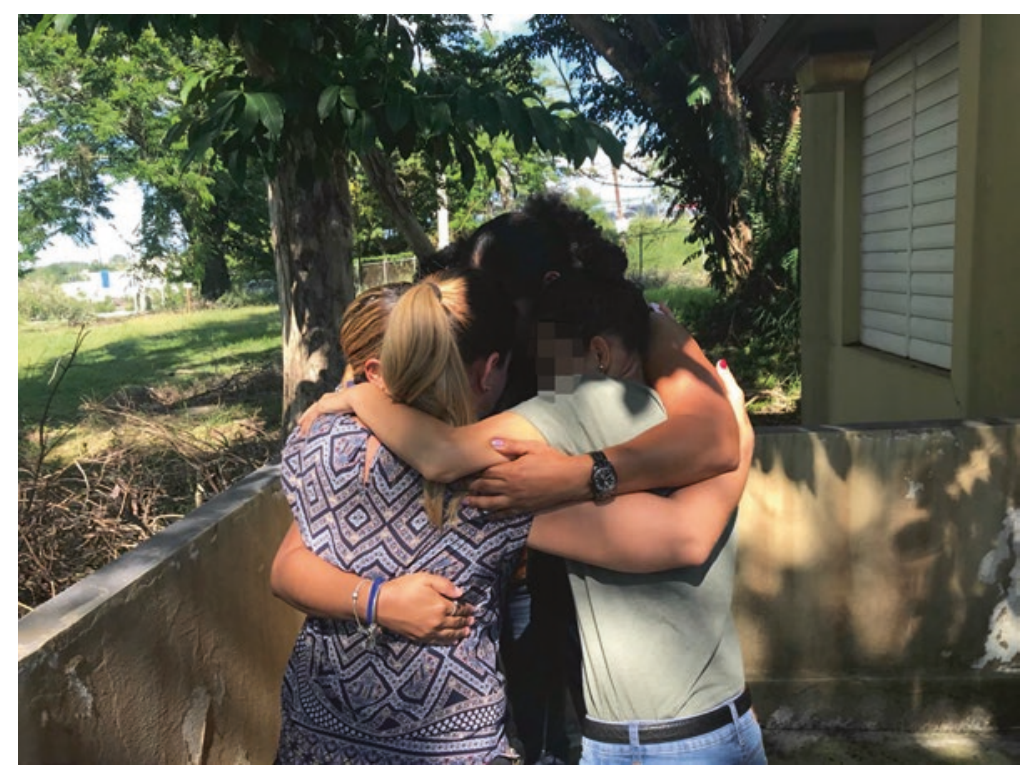

Fig. 6.4 Embracing each other through safe spaces 
The Encuentro CuidarNos represents an important step in providing a safe space to service providers, partners, and community leaders experiencing physical, emotional, and cognitive changes as a result of primary or secondary traumatic stress in the context of a disaster (Fig. 6.4). This space was built from a feminist perspective and took into consideration the diversity in the narrative and background of each person. Also, the Encuentro CuidarNos incorporated intervention to address the combination of primary and vicarious trauma and support psychological health and safety within the context of a natural disaster. As evidenced by Atkins and Burnett (2016) when they examined the relationship between engaging in disaster behavioral health training and interventions in trauma, indeed, individual and collective interventions may help to increase resiliency and reduce burnout among disaster behavioral health providers.

Nevertheless, beyond efforts to develop strategies to manage personal trauma caused by a disaster, organizational initiatives to work with vicarious trauma, and efforts to promote the well-being of communities, permanent organizational efforts are required to address the integral health of the victims. Attention from the state for the development of public and fiscal policies that support the promotion of health from a comprehensive standpoint_-including the development of protocols to manage the increase in gender violence after the occurrence of natural phenomena and the granting of adequate funds for organizations that work with this population-is equally necessary.

We discovered that summoning service providers to the Encuentro instead of to a traditional training placed the focus of attention on themselves and, as a result, opened a space to become vulnerable, identify emotions, and rely on somatic experiences. This Encuentro reaffirmed our belief that processing trauma by integrating different branches of the arts can expedite the following among participants: access to their memories, diverse language to express themselves and identify their emotions, and an overall state of well-being (see also Chap. 21, this volume). Hurricane María awoke our sense of vulnerability. It reminded us that life is ephemeral, that all we truly have is each other, and that we are part of a new social fabric-consolidated into solidarity and both individual and collective well-being.

Acknowledgements This project would not have been possible without the ongoing support of Coordinadora Paz para la Mujer (CPM) - The Puerto Rican Coalition against Domestic Violence and Sexual Assault. To learn more about CPM and their wonderful work, visit www.pazparalamujer.org.

\section{References}

Adamson, C. (2018). Trauma-informed supervision in the disaster context. The Clinical Supervisor, 37(1), 221-240.

Ahmed, S. H., \& Siddiqi, M. N. (2006). Essay: Healing through art therapy in disaster settings. The Lancet, 368, S28-S29. 
Alexander, R. (2018). Drawing disaster: Reflecting on six years of the Popoki Friendship Story project. Journal of International Cooperation Studies, 25(2), 69-96.

American Art Therapy Association. (2017). About art therapy. https://arttherapy.org/about-arttherapy/. Accessed 10 Oct 2018.

Atkins, C. D., \& Burnett, H. J., Jr. (2016). Specialized disaster behavioral health training: Its connection with response, practice, trauma health, and resilience. Disaster Health, 3(2), 57-65.

Bradshaw, S., \& Fordham, M. (2015). Double disaster: Disaster through a gender lens. In Hazards, risks and disasters in society (pp. 233-251). Oxford: Elsevier.

Bride, B. E. (2011). Collateral damage: The impact of caring for persons who have experienced trauma. (Video). Presentation for the Buffalo Center for Social Research Distinguished Scholar Series, Buffalo, NY. http://www.socialwork.buffalo.edu/resources/product.asp?id=21. Accessed 28 Sept 2018.

Bronfenbrenner, V. (1979). The ecology of human development: Experiments by nature and design. Cambridge, MA: Harvard University Press.

Buck, L., \& Axel, R. (1991). A novel multigene family may encode odorant receptors: A molecular basis for odor recognition. Cell, 65, 175-187.

Cox, K., \& Steiner, S. (2013). Workplace wellness. In Self-care in social work: A guide for practitioners, supervisors and administrators (pp. 137-158). NASW Press.

Cutter, S. L. (2017). The forgotten casualties redux: Women, children, and disaster risk. Global Environmental Change, 42, 117-121.

Delgado, J. A. (2018, September 23). Nearly 200,000 emigrated after María. El Nuevo Día. https:// www.elnuevodia.com/english/english/nota/nearly200000emigratedaftermaria-2. Accessed 25 Sept 2018.

Fisher, S. (2010). Violence against women and natural disasters: Findings from posttsunami Sri Lanka. Violence Against Women, 16(8), 902-918.

Heise L., Pitanguy H., \& Germain A. (1994). Violence against women: The hidden health burden. World Bank discussion papers 255.

Huss, E., Kaufman, R., Avgar, A., \& Shuker, E. (2016). Arts as a vehicle for community building and post-disaster development. Disasters, 40(2), 284-303.

Instituto de Estadísticas de Puerto Rico. (2016). Informe Sobre Desarrollo Humano Puerto Rico. Available at https://www.estadisticas.pr/files/Publicaciones/INFORME_DESARROLLO_ HUMANO_PUERTO_RICO_1.pdf. Accessed 8 Oct 2018.

Instituto de Estadísticas de Puerto Rico. (2017). 97 mil personas emigraron a estados unidos en el 2017 [Press release]. https://estadisticas.pr/files/Comunicados/CP_9_13_2018_SDC_1_year_ ACS_PRCS_2017.pdf. Accessed 8 Oct 2018.

Jackson, S. F., Fazal, N., Gravel, G., \& Papowitz, H. (2016). Evidence for the value of health promotion interventions in natural disaster management. Health Promotion International, 32(6), 1057-1066. https://doi.org/10.1093/heapro/daw029.

Juran, L., \& Trivedi, J. (2015). Women, gender norms, and natural disasters in Bangladesh. Geographical Review, 105(4), 601-611.

Karcher, O. P. (2017). Sociopolitical oppression, trauma, and healing: Moving toward a social justice art therapy framework. Art Therapy, 34(3), 123-128.

Kishore, N., Marqués, D., Mahmud, A., Kiang, M. V., Rodriguez, I., Fuller, A., et al. (2018). Mortality in Puerto Rico after Hurricane María. New England Journal of Medicine, 379, $162-177$.

Martinec, R. (2018). Dance movement therapy in the wider concept of trauma rehabilitation. Journal of Trauma and Rehabilitation, 1, 1. Retrieved from https://www.scitechnol.com/ peer-review/dance-movement-therapy-in-the-wider-concept-of-trauma-rehabilitation-gmCh. php?article_id $=7765$.

Naturale, A. (2015). How do we understand disaster-related vicarious trauma, secondary traumatic stress, and compassion fatigue? In G. Quitangon \& M. Evces (Eds.), Vicarious trauma and disaster mental health: Understanding risks and promoting resilience (pp. 93-110). New York: Routledge. 
Neumayer, E., \& Plümper, T. (2007). The gendered nature of natural disasters: The impact of catastrophic events on the gender gap in life expectancy, 1981-2002. Annals of the Association of American Geographers, 97(3), 551-566.

Olivares, E. y Incháustegui, T. (2011). Modelo ecológico para una vida libre de violencia de género. Comisión Nacional para Prevenir y Erradicar la Violencia contra las Mujeres: México D.F., pp. 21-24. Accessed: http://www.conavim.gob.mx/work/models/CONAVIM/Resource/309/1/ images/MoDecoFinalPDF.pdf.

Palm, K. M., Polusny, M. A., \& Follette, V. M. (2004). Vicarious traumatization: Potential hazards and interventions for disaster and trauma workers. Prehospital and Disaster Medicine, 19(1), 73-78.

Park, E.-K., \& Duarte, H. (2011). Epidemiología de desastres naturales. Revista Tempus Actas de Saúde Coletiva, 11-18.

Robles, F., Ferré-Sadurní, L., Fausset, R., \& Rivera, I. (2017, December 31). Enduring a day of misery in Puerto Rico's ruins. The New York Times, p. 16 (originally published October 1, 2017).

Rodríguez-Díaz, C. E. (2018). María in Puerto Rico: Natural disaster in a colonial archipelago. American Journal of Public Health, 108(1), 30-32.

Silva-Martínez, E. (2018). Violencia de género desde un enfoque centrado en trauma (pp. 7-13). Material educativo elaborado para Coordinadora Paz para la Mujer.

True, J. (2016). Gendered violence in natural disasters: Learning from New Orleans, Haiti and Christchurch. Aotearoa New Zealand Social Work, 25(2), 78-89.

United Nations Office for Disaster Risk Reduction (UNISDR). (2009). Terminology. https://www. unisdr.org/we/inform/terminology. Accessed 12 Oct 2018.

Wahl-Alexander, Z. (2017). Promoting emotional recovery following natural disasters through integrative art and physical activity programs. Online Harvard Health Policy Review. Available at http://www.hhpronline.org/articles/2017/10/8/promoting-emotional-recovery-following-natural-disasters-through-integrative-art-and-physical-activity-programs. Accessed 15 Oct 2018.

World Health Organization. (1986). The Ottawa Charter for Health Promotion. http://www.euro. who.int/_data/assets/pdf_file/0004/129532/Ottawa_Charter.pdf. Accessed 12 Oct 2018.

Open Access This chapter is licensed under the terms of the Creative Commons AttributionNonCommercial-NoDerivatives 4.0 International License (http://creativecommons.org/licenses/ by-nc-nd/4.0/), which permits any noncommercial use, sharing, distribution and reproduction in any medium or format, as long as you give appropriate credit to the original author(s) and the source, provide a link to the Creative Commons license and indicate if you modified the licensed material. You do not have permission under this license to share adapted material derived from this chapter or parts of it.

The images or other third party material in this chapter are included in the chapter's Creative Commons license, unless indicated otherwise in a credit line to the material. If material is not included in the chapter's Creative Commons license and your intended use is not permitted by statutory regulation or exceeds the permitted use, you will need to obtain permission directly from the copyright holder.

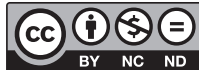

